\title{
ПОИСК ГЕНОМНЫХ ОБЛАСТЕЙ, НЕСУЩИХ ЛЕТАЛЬНЫЕ РЕЦЕССИВНЫЕ ВАРИАНТЫ У СВИНЕЙ ПОРОДЫ ДЮРОК
}

\author{
О.В. КОСТЮНИНА ${ }^{1}$, А.С. АБДЕЛЬМАНОВА ${ }^{1}$, Е.У. МАРТЫНОВА ${ }^{2}$, \\ Н.А. ЗИНОВЬЕВА 1
}

Эмбриональные потери у свиней достигают 30 \%, и необходимость их снижения не вызывает сомнений. В качестве одного из генетических факторов, обусловливающих эмбриональную смертность, рассматриваются LoF (loss of function) мутации, которые в гомозиготном состоянии приводят к терминации синтеза белка или синтезу нефункциональных белков. Если у крупного рогатого скота проводится интенсивный поиск LoF мутаций, то у свиней такие исследования носят менее масштабный характер. Полногеномные методы анализа с использованием SNP (single nucleotide polymorphism) чипов средней и высокой плотности, равномерно охватывающих весь геном, позволяют применять новые подходы для идентификации позиционных кандидатов для летальных рецессивных аллелей. Один из таких подходов - анализ степени неравновесия по сцеплению (LD) аллелей SNP маркеров. В представленной работе с использованием анализа степени неравновесия по сцеплению мы впервые провели поиск областей в геноме, которые могут быть связаны с летальными рецессивными эффектами у свиней породы дюрок, и выявили ряд наиболее значимых однонуклеотидных полиморфизмов, локализованных в пределах генов и играющих важную роль в различных физиологических процессах. Нашей целью был поиск областей, несущих презумптивно летальные рецессивные варианты у свиней (Sus scrofa) породы дюрок, на основании анализа неравновесия по сцеплению аллелей в SNP локусах. Исследования проводили на 715 хрячках (ООО «Селекционно-гибридный центр», Воронежская обл.) в 20172019 годах. Полногеномное генотипирование осуществляли с использованием ДНК-чипов Рorcine GGP HD («Neogene/Illumina, Inc.», CША), содержащих около 70 тыс. SNP. По результатам контроля качества для анализа был отобран 42981 полиморфный SNP. Поиск референтных последовательностей (reference sequence, rs) и уточнение их локализации проводили в базе данных Ensembl (http://www.ensembl.org). Функциональные аннотации генов выполняли с использованием базы данных GeneCards (http://www.genecards.org). Анализ сохранения генетического равновесия показал наличие 990 SNP с отсутствием одного из гомозиготных генотипов $(2,30 \%$ от общего числа полиморфных SNP), которые были распределены между всеми хромосомами свиней, в том числе $205 \mathrm{SNP}$, находившихся в неравновесии по сцеплению $(0,48 \%)$. Наибольшей долей SNP, которые находились в неравновесии по сцеплению, характеризовались хромосомы SSC9 $(0,85 \%), \operatorname{SSC5}(0,77 \%), \operatorname{SSC} 7(0,68 \%)$ и SSC2 (0,68 \%), наименьшей - хромосомы $\operatorname{SSC13}(0,28 \%), \operatorname{SSC} 4(0,29 \%)$ и SSC10 (0,30 \%). Для 52 SNP, 25 из которых были локализованы внутри генов, различия в частоте наблюдаемой и ожидаемой гетерозиготности оказались статистически значимы (p < 0,01). Среди SNP, расположенных в межгенных областях, два (rs81350198 и rs81337222) были ассоциированы с хозяйственно полезными фенотипами (по результатам ранее проведенных GWAS исследований). Для 12 из 25 выявленных позиционных генов-кандидатов (OR4C45, EPHB4, EML4, SLC4A1AP, ZFAT, CELSR2, NEGR1, LRRC32, MYOCD, HUNK, RPH3A и DOCKI) имеется информация о роли в различных процессах в организме млекопитающих, включая развитие нервной системы, ангиогенез, кардиогенез, дифференцировку клеток, апоптоз и многих другие. Интеграция в программы селекционно-племенной работы ДНК маркеров, ассоциированных с летальными фенотипами, в дополнение к ДНК маркерам, идентифицированным по результатам GWAS исследований, существенно повысит эффективность программ маркерной и геномной селекции в свиноводстве.

Ключевые слова: свиньи, неравновесие по сцеплению, летальные варианты, LoF (loss of function), однонуклеотидные полиморфизмы.

Эмбриональные потери оказывают значительное негативное влияние на эффективность и рентабельность отраслей животноводства. В свиноводстве они составляют до 30 \% (1). Среди генетических факторов, ассоциированных с эмбриональной смертностью, рассматриваются так называемые LoF (loss of function) мутации, которые в гомозиготном состоянии

\footnotetext{
* При выполнении исследований использовалось оборудование ЦКП «Биоресурсы и биоинженерия сельскохозяйственных животных» ВИЖ им. академика Л.К. Эрнста. Исследования выполнены в рамках ГЗ 0445-2019-0026, рег. № AAAA-A18-118021590138-1.
} 
приводят к терминации синтеза или синтезу нефункциональных белков (2). Наиболее активно поиск LoF мутаций осуществляется у крупного рогатого скота различных пород с использованием соответствующих тестсистем диагностики в практике сельскохозяйственных предприятий (3). В свиноводстве исследования LoF мутаций пока носят менее масштабный характер. Для идентификации мутаций, приводящих к видимым изменениям, часто используется подход, основанный на анализе родословных (4). Однако он непригоден для идентификации LoF мутаций, поскольку их фенотипический эффект проявляется в снижении многоплодия, что может быть обусловлено рядом других причин.

Развитие методов анализа полногеномных данных открыло новые возможности для поиска генетических факторов, ассоциированных с эмбриональной смертностью. Чтобы успешно использовать ДНК маркеры для выявления летальных рецессивных вариантов, вызывающих пренатальную смертность, требуется достаточная степень неравновесия по сцеплению (linkage disequilibrium, LD) между маркерным алеллем (аллелями) и летальным вариантом (вариантами) (5). Два аллеля в различных локусах находятся в неравновесии по сцеплению, если частота состоящего из них гаплотипа значимо отличается от частоты, ожидаемой при случайной сегрегации. Для лучшего выявления редких и нетипичных вариантов, которые не включены в общий массив генотипируемых однонуклеотидных полиморфизмов (single nucleotide polymorphism, SNP), применяют гаплотипический подход. Фазирование генотипических данных обеспечивает высокую четкость гетерогенности гаплотипов и позволяет сделать вывод о гаплотипах негенотипированных предков и животных, которых генотипировали с использованием матриц более низкой плотности. Такой подход был применен при выявлении летального рецессивного гаплотипа, связанного с числом мертворожденных поросят (6).

M.F.L. Derks с соавт. (7) искали летальные аллели, сегрегирующие в популяциях свиней пород ландрас $(n=28085)$ и дюрок $(n=11255)$, с использованием SNP-чипа средней плотности («Illumina, Inc.», США). Применив метод с перекрывающимся скользящим окном, они обнаружили один сильный кандидатный гаплотип (DU1), несущий летальный рецессивный аллель в популяции свиней породы дюрок, и четыре гаплотипа-кандидата у породы ландрас (LA1-4). Среди гаплотипов DU1, LA1 и LA3 не выявлялись гомозиготы, в то время как их ожидаемое чило составляло соответственно 26, 126 и 16. Для гаплотипов LA2 и LA4 также отмечалось нарушение генетического равновесия, что может свидетельствовать о неполном LD гаплотипов с летальными рецессивными мутациями. Показано влияние всех пяти гаплотипов на значительное снижение общего количества рожденных поросят (total number born, TNB) и числа живорожденных поросят (number born alive, NBA). Вместе с тем существенного увеличения числа мертворожденных или мумифицированных поросят не наблюдали, что свидетельствует о гибели гомозиготных носителей на ранних этапах супоросности (7).

В представленной работе с использованием анализа степени неравновесия по сцеплению мы впервые провели поиск областей в геноме, которые могут быть связаны с летальными рецессивными эффектами у свиней породы дюрок и выявили ряд наиболее значимых однонуклеотидных полиморфизмов, локализованных в пределах генов и играющих важную роль в различных физиологических процессах.

Нашей целью был поиск областей, несущих презумптивно леталь- 
ные рецессивные варианты у свиней (Sus scrofa) породы дюрок, на основании анализа степени неравновесия по сцеплению аллелей в SNP локусах.

Методика. Исследования проводили на 715 хрячках породы дюрок (ООО «Селекционно-гибридный центр», Воронежская обл., 2017 2019 годы).

Биоматериалом для выделения геномной ДНК с использованием набора реагентов ДНК-Экстран-2 (ООО «Синтол», Россия) были пробы ткани (ушной выщип). Качество и концентрацию ДНК определяли с помощью флуориметра Qubit 2.0 («Invitrogen/Life Technologies», США) и спектрофотометра NanoDrop8000 («Thermo Fisher Scientific», США).

Полногеномное генотипирование проводили с использованием чипов GGP Porcine («Neogene/Illumina, Inc.», США), содержащих около 70 тыс. SNP. В пакете Plink 1.9 (http://zzz.bwh.harvard.edu/plink/) по параметрам качества генотипирования (выше 90 \%), частоты минорных аллелей (не более 0,5 \%) и неравновесия по сцеплению (с шагом $50 \mathrm{~kb}$ ) (8) для анализа отобрали 42981 полиморфный SNP. Поиск референтных последовательностей (reference sequence, rs) и уточнение их локализации осуществляли в базе данных Ensembl (http://www.ensembl.org, дата обращения: август 2019 года). Функциональные аннотации генов выполняли с помощью базы данных GeneCards (http://www.genecards.org, дата обращения: август 2019 года).

Результаты. Анализ сохранения генетического равновесия показал наличие 990 SNP с отсутствием одного из гомозиготных генотипов, из которых 205 SNP находились в неравновесии по сцеплению, что составляло соответственно 2,30 и 0,48 \% от общего числа полиморфных SNP (рис.).

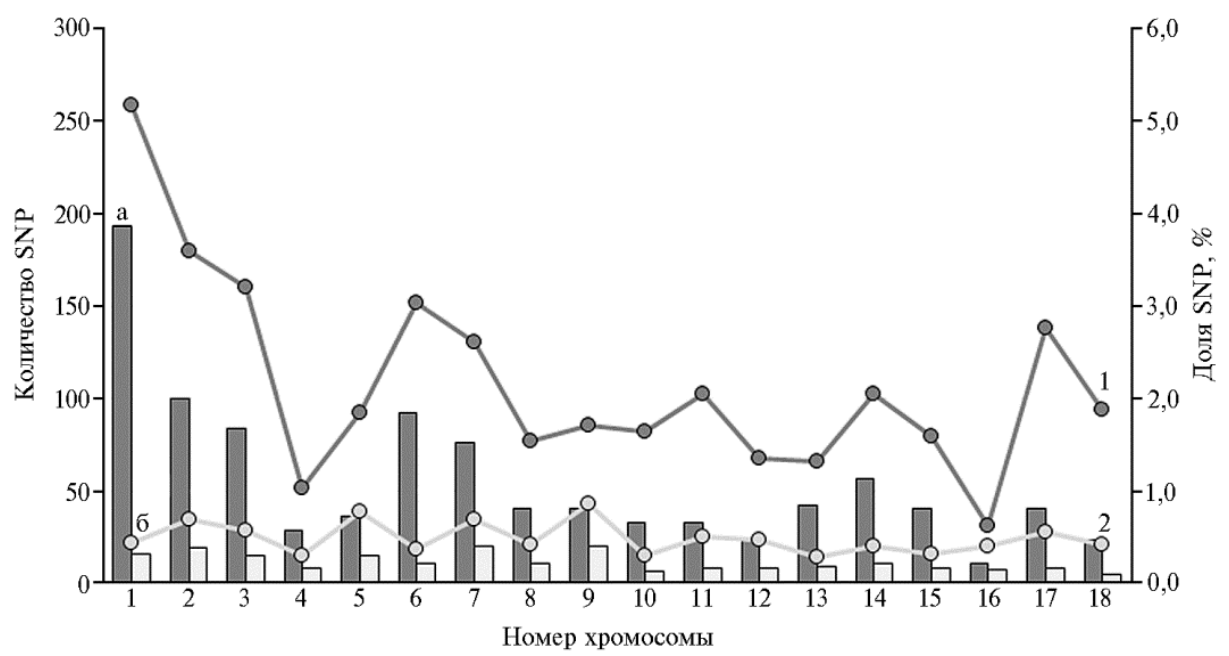

Хромосомальное распределение SNP (single nucleotide polymorphism), по которым зафиксировано отсутствие одного из гомозиготных вариантов и нарушение неравновесия по сцеплению у хрячков (Sus scrofa) породы дюрок: а - число SNP, для которых отсутствует один из гомозиготных генотипов, б - число SNP, находящихся в неравновесии по сцеплению (столбчатая диаграмма); 1 - доля SNP, для которых отсутствует один из гомозиготных генотипов, от общего числа полиморфных SNP на хромосоме, 2 - доля SNP, находящихся в неравновесии по сцеплению, от общего числа полиморфных SNP на хромосоме (линейный график) ( $n=715$, ООО «Селекционно-гибридный центр», Воронежская обл., 2017-2019 годы).

Наибольшее число SNP, для которых наблюдалось отсутствие одного из гомозиготных генотипов, было локализовано на 1-й хромосоме (Sus scrofa chromosome 1, SSC1) - 193 SNP, а находящихся в неравновесии по сцеплению - на SSC7 и SSC9 (20 SNP), наименьшее - соответ- 
ственно на SSC16 (11 SNP) и SSC18 (5 SNP). Наибольшей долей SNP, находящихся в неравновесии по сцеплению, характеризовались хромосомы SSC9 (0,85 \%), SSC5 (0,77 \%), SSC7 (0,68 \%) и $\operatorname{SSC} 2(0,68 \%)$, наименышей $-\operatorname{SSC} 13(0,28 \%), \operatorname{SSC} 4(0,29 \%)$ и $\operatorname{SSC} 10(0,30 \%)$.

Наиболее значимые полиморфизмы, для которых отмечалось неравновесие по сцеплению ( $\mathrm{p} \leq 0,01)$, представлены в таблице 1.

1. Наиболее значимые однонуклеотидные полиморфизмы, находящиеся в неравновесном сцеплении у хрячков (Sus scrofa) породы дюрок $(n=715$, ООО «Селекционно-гибридный центр», Воронежская обл., 2017-2019 годы)

\begin{tabular}{|c|c|c|c|c|c|c|c|c|}
\hline $\mathrm{SSC}$ & $\mathrm{RS}$ & $\begin{array}{l}\text { Позиция на хромо- } \\
\text { соме (сборка 10.2) }\end{array}$ & AlA1 & A1A2 & $\mathrm{A} 2 \mathrm{~A} 2$ & $\mathrm{H}_{\mathrm{o}}$ & $\mathrm{H}_{\mathrm{e}}$ & $\mathrm{p}$ \\
\hline 1 & rs81350198 & 226188042 & 0 & 163 & 547 & 0,2296 & 0,2032 & $5,1 \times 10^{-5}$ \\
\hline 1 & rs80795638 & 277854630 & 0 & 227 & 440 & 0,3403 & 0,2824 & $1,7 \times 10^{-10}$ \\
\hline 1 & rs81002425 & 296461073 & 0 & 700 & 9 & 0,9873 & 0,4999 & $5,4 \times 10^{-195}$ \\
\hline 1 & rs334911415 & 312050746 & 0 & 662 & 45 & 0,9364 & 0,4980 & $1,2 \times 10^{-152}$ \\
\hline 1 & rs342062641 & 312083991 & 0 & 645 & 63 & 0,9110 & 0,4960 & $1,2 \times 10^{-137}$ \\
\hline 2 & rs81362641 & 12082068 & 0 & 618 & 92 & 0,8704 & 0,4916 & $1,7 \times 10^{-117}$ \\
\hline 2 & rs81255095 & 14056188 & 0 & 345 & 309 & 0,5275 & 0,3884 & $5,2 \times 10^{-28}$ \\
\hline 2 & rs319913462 & 14759005 & 0 & 522 & 126 & 0,8056 & 0,4811 & $4,0 \times 10^{-84}$ \\
\hline 2 & rs323641934 & 15384171 & 0 & 537 & 172 & 0,7574 & 0,4706 & $1,1 \times 10^{-76}$ \\
\hline 2 & rs343381067 & 15551096 & 0 & 665 & 45 & 0,9366 & 0,4980 & $2,0 \times 10^{-153}$ \\
\hline 2 & rs80911461 & 160111983 & 0 & 186 & 506 & 0,2688 & 0,2327 & $7,8 \times 10^{-7}$ \\
\hline 3 & rs344115015 & 8107291 & 0 & 139 & 570 & 0,1961 & 0,1768 & $9,7 \times 10^{-4}$ \\
\hline 3 & rs323044318 & 104257589 & 0 & 120 & 590 & 0,1690 & 0,1547 & $6,4 \times 10^{-3}$ \\
\hline 3 & rs81375606 & 116445052 & 0 & 124 & 586 & 0,1746 & 0,1594 & $4,1 \times 10^{-3}$ \\
\hline 3 & rs81375903 & 118615471 & 0 & 142 & 568 & 0,2000 & 0,1800 & $6,0 \times 10^{-4}$ \\
\hline 3 & rs80828678 & 132719179 & 0 & 348 & 305 & 0,5329 & 0,3909 & $1,9 \times 10^{-28}$ \\
\hline 3 & rs327044542 & 141265677 & 0 & 170 & 540 & 0,2394 & 0,2108 & $1,8 \times 10^{-5}$ \\
\hline 4 & rs331053365 & 4353353 & 0 & 156 & 554 & 0,2197 & 0,1956 & $1,4 \times 10^{-4}$ \\
\hline 4 & rs323787335 & 7185799 & 0 & 591 & 114 & 0,8383 & 0,4869 & $1,8 \times 10^{-103}$ \\
\hline 4 & rs 343205058 & 109273333 & 0 & 604 & 106 & 0,8507 & 0,4889 & $5,1 \times 10^{-109}$ \\
\hline 4 & rs80949619 & 121334654 & 0 & 123 & 587 & 0,1732 & 0,1582 & $6,7 \times 10^{-3}$ \\
\hline 5 & rs340620949 & 1453085 & 0 & 163 & 546 & 0,2299 & 0,2035 & $5,1 \times 10^{-5}$ \\
\hline 5 & rs81323749 & 18046364 & 0 & 184 & 526 & 0,2592 & 0,2256 & $2,4 \times 10^{-6}$ \\
\hline 5 & rs80875559 & 99245749 & 0 & 119 & 591 & 0,1676 & 0,1536 & $6,5 \times 10^{-3}$ \\
\hline 6 & rs81337222 & 13141 & 0 & 709 & 1 & 0,9986 & 0,5000 & $3,3 \times 10^{-210}$ \\
\hline 6 & rs81476539 & 67022132 & 0 & 237 & 471 & 0,3347 & 0,2787 & $6,2 \times 10^{-11}$ \\
\hline 6 & rs337799081 & 130798722 & 0 & 130 & 580 & 0,1831 & 0,1663 & $2,5 \times 10^{-3}$ \\
\hline 7 & rs319008071 & 27213610 & 0 & 237 & 451 & 0,3445 & 0,2851 & $3,0 \times 10^{-11}$ \\
\hline 7 & rs80944793 & 129041116 & 0 & 120 & 590 & 0,1690 & 0,1547 & $6,4 \times 10^{-3}$ \\
\hline 7 & rs331172717 & 131889604 & 0 & 614 & 79 & 0,8860 & 0,4935 & $4,5 \times 10^{-122}$ \\
\hline 8 & rs81399201 & 31445286 & 0 & 134 & 576 & 0,1887 & 0,1709 & $1,6 \times 10^{-3}$ \\
\hline 8 & rs322099448 & 78592741 & 0 & 580 & 127 & 0,8204 & 0,4839 & $5,5 \times 10^{-97}$ \\
\hline 9 & rs343201786 & 11913668 & 0 & 137 & 573 & 0,1930 & 0,1743 & $9,8 \times 10^{-4}$ \\
\hline 9 & rs346413844 & 12946073 & 0 & 638 & 3 & 0,9953 & 0,5000 & $2,7 \times 10^{-185}$ \\
\hline 9 & rs81337172 & 15049063 & 0 & 125 & 585 & 0,1761 & 0,1606 & $4,0 \times 10^{-3}$ \\
\hline 10 & rs81305281 & 76905575 & 0 & 520 & 189 & 0,7334 & 0,4645 & $4,7 \times 10^{-70}$ \\
\hline 11 & rs80816476 & 939424 & 0 & 131 & 579 & 0,1845 & 0,1675 & $2,5 \times 10^{-3}$ \\
\hline 11 & rs325221950 & 21018670 & 0 & 145 & 561 & 0,2054 & 0,1843 & $3,7 \times 10^{-4}$ \\
\hline 11 & rs329067201 & 21371677 & 0 & 148 & 562 & 0,2085 & 0,1867 & $3,7 \times 10^{-4}$ \\
\hline 12 & rs81478101 & 26712700 & 0 & 697 & 13 & 0,9817 & 0,4998 & $2,4 \times 10^{-189}$ \\
\hline 12 & rs81436301 & 50907615 & 0 & 342 & 368 & 0,4817 & 0,3657 & $1,9 \times 10^{-24}$ \\
\hline 12 & rs81228589 & 59880454 & 0 & 137 & 573 & 0,1930 & 0,1743 & $9,8 \times 10^{-4}$ \\
\hline 13 & rs329645817 & 5325304 & 0 & 320 & 390 & 0,4507 & 0,3491 & $5,3 \times 10^{-21}$ \\
\hline 13 & rs322958990 & 205932444 & 0 & 276 & 404 & 0,4059 & 0,3235 & $7,0 \times 10^{-16}$ \\
\hline 13 & rs 328137225 & 218478357 & 0 & 135 & 575 & 0,1901 & 0,1721 & $1,6 \times 10^{-3}$ \\
\hline 14 & rs80958173 & 41518669 & 0 & 125 & 585 & 0,1761 & 0,1606 & $4,0 \times 10^{-3}$ \\
\hline 14 & rs80862470 & 95881035 & 0 & 624 & 86 & 0,8789 & 0,4927 & $1,6 \times 10^{-121}$ \\
\hline 14 & rs80993446 & 148199735 & 0 & 128 & 582 & 0,1803 & 0,1640 & $4,3 \times 10^{-3}$ \\
\hline 15 & rs337254355 & 2154617 & 0 & 138 & 570 & 0,1949 & 0,1759 & $9,6 \times 10^{-4}$ \\
\hline 16 & rs334615079 & 81560836 & 0 & 381 & 321 & 0,5427 & 0,3955 & $5,0 \times 10^{-32}$ \\
\hline 17 & rs80988530 & 36703557 & 0 & 587 & 68 & 0,8962 & 0,4946 & $4,3 \times 10^{-120}$ \\
\hline 17 & rs345268841 & 66549094 & 0 & 258 & 450 & 0,3644 & 0,2980 & $5,09 \times 10^{-13}$ \\
\hline
\end{tabular}

Пр и м е ч а н и е. SSC - номер хромосомы, RS - референтная последовательность, А1 - аллель 1, A2 аллель $2, \mathrm{H}_{\mathrm{o}}$ - наблюдаемая гетерозиготность, $\mathrm{H}_{\mathrm{e}}$ - ожидаемая гетерозиготность, $\mathrm{p}-$ уровень статистической значимости.

Всего идентифицировали 52 значимых полиморфизма, для которых 
различия в наблюдаемой и ожидаемой частоте гетерозиготности были статистически значимы. Эти SNP распределялись между 17 хромосомами (кроме SSC18), в том числе 5 SNP на SSC1, 6 - на SSC2, 6 - на SSC3, 4 на SSC4, 3 - на SSC5, 3 - на SSC6, 3 - на SSC7, 2 - на SSC8, 3 - на SSC9, 1 - на SSC10, 3 - на SSC11, 3 - на SSC12, 3 - на SSC13, 3 - на SSC14, 1 - на SSC15, 1 - на SSC16, 2 - на SSC17. Два SNP (rs81350198 на SSC1 и rs81337222 на SSC6) по результатам GWAS (genome-wide association study, полногеномный поиск ассоциаций) идентифицированы в качестве ДНК маркеров, ассоциированных с хозяйственно полезными фенотипами $(9,10)$. Полиморфизм rs81350198 ассоциирован со вкусом мяса у некастрированных хряков, обусловленным накоплением скатола и андростенона в период половой зрелости (9). Для полиморфизма rs81337222 выявлена умеренная ассоциация $\left(\mathrm{p}=2,4 \times 10^{-5}\right)$ с возникновением пупочной грыжи (10). Несмотря на то, что в непосредственной близости от rs81337222 не были идентифицированы QTL (quantitative trait loci), которые связаны с пупочной грыжей, и не локализованы описанные гены, для которых подтверждена связь с этим фенотипическим признаком, его презумптивный QTL может быть расположен в up-stream регионе SSC6 (6:3 814 0213870 534), выявленном при анализе CNV (copy number variation) (11). Следовательно, в начале SSC6 имеются регуляторные области, которые требуют дополнительного исследования.

2. Однонуклеотидные полиморфизмы, локализованные внутри генов и презумптивно ассоциированные с летальными рецессивные вариантами у свиней (Sus scrofa) породы дюрок ( $n=715$, ООО «Селекционно-гибридный центр», Воронежская обл., 2017-2019 годы)

\begin{tabular}{|c|c|c|c|}
\hline RS (p) & $\begin{array}{l}\text { Название гена } \\
\text { в системе Ensembl }\end{array}$ & Ген-кандидат & Тип мутации \\
\hline 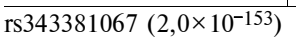 & ENSSSCG00000031436 & OR4C45 & Замена внутри интрона \\
\hline rs344115015 $\left(9,7 \times 10^{-4}\right)$ & ENSSSCG00000007675 & ЕРНB4 & Замена внутри интрона \\
\hline rs323044318 $\left(6,4 \times 10^{-3}\right)$ & ENSSSCG00000008467 & EML4 & Замена внутри интрона \\
\hline rs81375606 $\left(4,1 \times 10^{-3}\right)$ & ENSSSCG00000008533 & - & Замена внутри интрона \\
\hline rs81375903 $\left(6,0 \times 10^{-4}\right)$ & ENSSSCG00000008549 & $S L C 4 A 1 A P$ & Замена на 3'-конце гена \\
\hline rs327044542 $\left(1,8 \times 10^{-5}\right)$ & ENSSSCG00000049737 & - & Замена внутри интрона \\
\hline rs323787335 $\left(1,8 \times 10^{-103}\right)$ & ENSSSCG00000030947 & $Z F A T$ & Мутация в 3'-UTR \\
\hline rs343205058 $\left(5,1 \times 10^{-109}\right)$ & ENSSSCG00000006694 & - & Замена внутри интрона \\
\hline rs80949619 (6,7×10-3) & ENSSSCG00000034360 & CELSR2 & Замена внутри интрона \\
\hline rs340620949 $\left(5,1 \times 10^{-5}\right)$ & ENSSSCG00000024474 & - & Замена на 3'-конце гена \\
\hline rs81323749 $\left(2,4 \times 10^{-6}\right)$ & ENSSSCG00000024474 & - & Замена на 3'-конце гена \\
\hline rs81476539 $\left(6,2 \times 10^{-11}\right)$ & ENSSSCG00000003444 & - & Замена на 3'-конце гена \\
\hline rs337799081 $\left(2,5 \times 10^{-3}\right)$ & ENSSSCG00000025085 & NEGR1 & Замена внутри интрона \\
\hline rs319008071 $\left(3,0 \times 10^{-11}\right)$ & ENSSSCG00000001395 & - & Синонимическая мутация \\
\hline rs343201786 $\left(9,8 \times 10^{-4}\right)$ & ENSSSCG00000014869 & LRRC32 & Мутация в 3'-UTR \\
\hline rs325221950 $\left(3,7 \times 10^{-4}\right)$ & ENSSSCG00000045677 & - & Замена на 3'-конце гена \\
\hline rs81436301 $\left(1,9 \times 10^{-24}\right)$ & ENSSSCG00000017853 & - & Замена на 3'-конце гена \\
\hline rs81228589 $\left(9,8 \times 10^{-4}\right)$ & ENSSSCG00000031988 & $M Y O C D$ & Замена внутри интрона \\
\hline rs322958990 $\left(7,0 \times 10^{-16}\right)$ & ENSSSCG00000029392 & HUNK & Замена внутри интрона \\
\hline rs80958173 $\left(4,0 \times 10^{-3}\right)$ & ENSSSCG00000009883 & RPH3A & Замена внутри интрона \\
\hline rs80862470 $\left(1,6 \times 10^{-121}\right)$ & ENSSSCG00000043778 & - & Замена внутри интрона \\
\hline rs80993446 $\left(4,3 \times 10^{-3}\right)$ & ENSSSCG00000035045 & DOCK1 & Замена внутри интрона \\
\hline rs337254355 $\left(9,6 \times 10^{-4}\right)$ & ENSSSCG00000044919 & - & Замена внутри интрона \\
\hline rs80988530 $\left(4,3 \times 10^{-120}\right)$ & ENSSSCG00000007155 & C20orf194 & Замена внутри интрона \\
\hline rs345268841 $\left(5,09 \times 10^{-13}\right)$ & ENSSSCG00000007525 & - & Миссенс-мутация \\
\hline \multicolumn{4}{|c|}{ 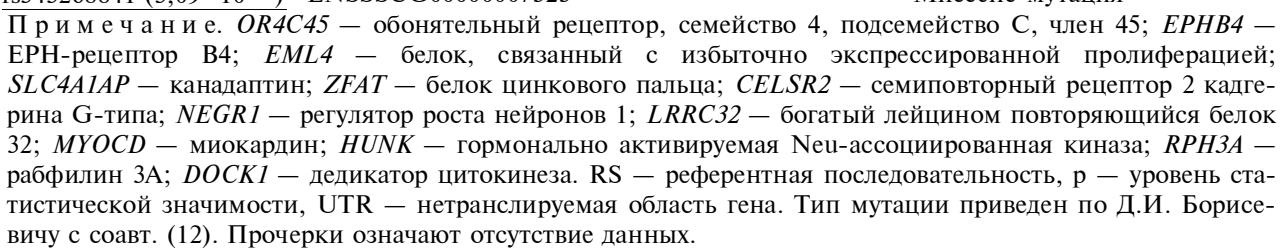 } \\
\hline
\end{tabular}


Анализ геномных регионов, в которых мы обнаружили SNP, показал, что 25 SNP находились внутри генов. По типу локализации большинство SNP представляли собой мутации внутри интронов (всего 15 мутаций). Были также обнаружены замены в 3'-последовательности генов (6 мутаций) и в 3'-нетранслируемой области гена (2 мутации), а также одна миссенс-мутация и одна синонимическая мутация (табл. 2).

Для 12 из 25 выявленных позиционных генов-кандидатов известна информация об их роли в различных процессах в организме млекопитающих. Так, ген OR4C45 кодирует белок обонятельного рецептора (OP), который важен для поддержания кишечного гомеостаза. ОР экспрессируется в энтерохромаффинных клетках слизистой оболочки. Одорантные лиганды через ОР, присутствующие в клетках энтерохромаффина, вызывают высвобождение серотонина, который контролирует моторику и секрецию кишечника и вовлечен в патологические состояния, такие как рвота, диарея (13). Сообщается о роли ОР лиганда в регуляции проницаемости эпителия и секреции электрогенных анионов в толстой кишке человека (14). EPHB4 играет особую роль в разнообразных биологических процессах, таких как развитие нейронов, гомеостаз костей, ангиогенез (15). Генетически модифицированные эмбрионы мышей, гомозиготные по аллелю EphB4taulacZ, имели сердечно-сосудистые дефекты и характеризовались эмбриональной летальностью с очень высокой пенетрантностью. У таких эмбрионов отмечалось замедление роста, отсутствие кровотока и остановка развития сердца (16). EML4 - плохо охарактеризованный белок, ассоциированный с микротрубочками. Предполагается, что его естественная функция заключается в стабилизации микротрубочек в аксонах и дендритах нейрональных клеток. Химерный EML4-ALK обусловливает развитие рака легких у человека (17).

Канадаптин (SLC4A1AP) - ядерный белок с неизвестной функцией, который широко экспрессируется в тканях млекопитающих. Повсеместное распространение канадаптина у млекопитающих предполагает, что он должен играть важную физиологическую роль (18). ZFAT принимает участие в развитии и периферическом гомеостазе Т-клеток. Имеются сведения, что делеция в гене Zfat у мышей приводит к эмбриональной смерти и нарушает примитивный гематопоэз в кровяных островках желточного мешка $(19,20)$. У свиней ZFAT связан с подверженностью энтеротоксигенной инфекции, вызываемой Escherichia coli (21). CELSR2 экспрессируется во всех областях мозга и регулирует поддержание и рост дендритов. У гомозиготных по мутации в CELSR2 мышах развивается гидроцефалия из-за снижения количества, размера и ориентации эпендимальных ресничек (22). NEGR1 участвует в регуляции разрастания нейритов в развивающемся мозге (23). В результате поиска QTL, связанных с ожирением у человека и свиней, выявлены три наиболее вероятных гена, в том числе $N E G R 1$, ответственный за генетическую предрасположенность к распространенным формам ожирения, в особенности за толщину подкожного жира (24). LRRC32 функционирует как рецептор для молекул латентного трансформирующего фактора роста, он был обнаружен в регуляторных Т-клетках (25). Отмечается его важная роль в иммунной регуляции. GWAS исследования показали ассоциацию между rs11236909, расположенным примерно на расстоянии $58 \mathrm{~kb}$ up-stream от гена $L R R C 32$, и некоторыми параметрами подвижности сперматозоидов человека (26). 
MYOCD вносит вклад в развитие сердца и дифференцировку кардиомиоцитов. Отмечается, что у мышей-мутантов с нокаутом гена MYOCD развивалась дилатационная кардиомиопатия, которая сопровождалась нарушением структурной организации кардиомиоцитов и выраженной депрессией систолической функции (27). Функции гена HUNK еще уточняются. Вероятно, он участвует в переносе фосфорсодержащих групп, проявлении активности трансферазы и тирозинкиназы белка. RPH3A играет важную роль в адгезии нейтрофилов на эндотелиальных клетках во время воспалительных реакций (28). DOCK1 регулирует фагоцитоз, слияние миобластов и миграцию клеток, участвует в эмбриональном развитии. Выявленное уменьшение развития всех тканей скелетных мышц у эмбрионов с нокаутом по Dock1 позволило идентифицировать DOCK1 как важный регулятор стадии слияния в миогенезе у млекопитающих (29). Информацию о роли гена ENSSSCG00000024474 в открытых базах данных обнаружить не удалось, но при GWAS анализе метилирования ДНК у сальных, постных и миниатюрных пород свиней он был идентифицирован как дифференциально метилированная область (30). Ген C20orf194 (194-я открытая рамка считывания 20-й хромосомы) кодирует неохарактеризованный белок с С-концевой областью спиральной катушки. Ген расположен на хромосоме 20p13 в области $1,8 \mathrm{Mb}$, связанной с фенотипом спиноцеребеллярной атаксии у человека. Исследования S. Ponsuksili c соавт. (31) по определению регионов, связанных с поведенческими реакциями у свиней породы ландрас, показали наличие в пределах этого гена SNP rs80988530, выявленного нами в регионе с высоким неравновесным сцеплением.

Таким образом, полногеномные исследования, которые мы проведенные с использованием чипов GGP Porcine HD, позволили определить регионы, мутации в которых могут стать причиной возникновения летальных эффектов. Наиболее значимые однонуклеотидные полиморфизмы, находящиеся в неравновесном сцеплении у хрячков породы дюрок, локализованы нами в пределах следующих генов: OR4C45 - обонятельный рецептор, семейство 4, подсемейство С, член 45; ЕРНВ4 - ЕРН-рецептор B4; EML4 - белок, связанный с избыточно экспрессированной пролиферацией; SLC4A1AP - канадаптин; ZFAT - белок цинкового пальца; CELSR2 - семиповторный рецептор 2 кадгерина G-типа; NEGR1 - регулятор роста нейронов 1 ; LRRC32 - богатый лейцином повторяющийся белок 32; MYOCD - миокардин; HUNK - гормонально активируемая Neu-ассоциированная киназа; $R P H 3 A$ - рабфилин $3 \mathrm{~A} ; D O C K 1$ - дедикатор цитокинеза. Практически для каждого идентифицированного генакандидата к настоящему времени охарактеризована его важная роль в различных процессах: развитии нервной системы, ангиогенезе, кардиогенезе, дифференцировке клеток, апоптозе и др. У человека многие из этих генов ассоциированы с заболеваниями различных органов и тканей, не исключено их участие в возникновении летальных эффектов у свиней. Понимание процессов, протекающих в период роста и развития эмбрионов, и использование этих знаний при анализе фактических данных зоотехнического учета расширят арсенал средств, позволяющих своевременно предлагать подходы по генетическому совершенствованию племенной продукции. Интеграция в программы селекционно-племенной работы ДНК маркеров, ассоциированных с летальными фенотипами, в дополнение к ДНК маркерам, идентифицированным по результатам GWAS анализа, существенно повысит эффективность программ маркерной и геномной селекции в сви- 
142132 Россия, Московская обл., г.о. Подольск, пос. Дубровицы, 60, e-mail: kostolan@mail.ru $\bowtie$, preevetic@mail.ru,n_zinovieva@mail.ru;

2Центр наук о жизни, АНОА ВО Сколковский институт науки и технологий,

143026 Россия, г. Москва, ул. Нобеля, 3,

e-mail: elenamartynovaster@gmail.com

Sel'skokhozyaistvennaya biologiya [Agricultural Biology], 2020, V. 55, № 2, pp. 275-284

\title{
SEARCH FOR GENOMIC REGIONS CARRYING THE LETHAL GENETIC VARIANTS IN THE DUROC PIGS
}

\author{
O.V. Kostyunina ${ }^{1}$, A.S. Abdelmanova ${ }^{1}$, E.U. Martynova ${ }^{2}$, N.A. Zinovieval
}

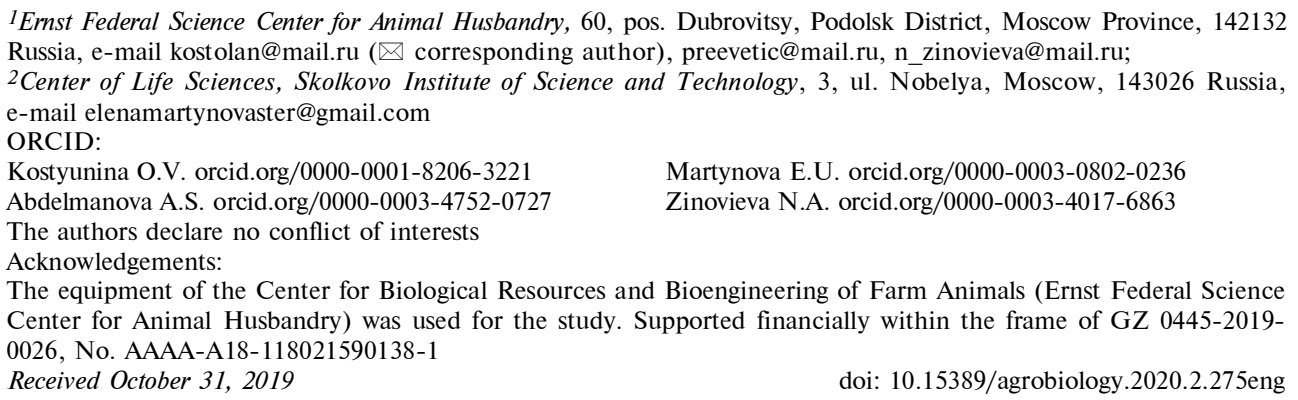

\section{Abstract}

The necessity to address the problem of reducing embryonic losses, which in pigs are estimated at the level up to $30 \%$, is not in doubt. LoF (Loss of Function) mutations, which in the homozygous state can lead to the termination of synthesis or synthesis of non-functional proteins, are considered as one of the genetic factors that cause embryonic mortality. While in cattle, an intensive search for LoF mutations is carried out, in pigs, studies of such mutations are still performed on a smaller scale. Whole-genome analysis using medium- and high-density SNP chips which are uniformly covering the entire genome allows researchers to apply new approaches to identify positional candidates for lethal recessive variants. One of such approaches is the analysis of the level of the linkage disequilibrium (LD) of alleles of SNP markers. The aim of our research was to search for genomic regions that carry presumed lethal recessive variants in Duroc pigs, based on the analysis of the linkage disequilibrium of alleles in SNP loci. Studies were carried out with 715 Duroc boars bred in JSC Top Gen (Voronezh region) in 2017-2019. Whole-genome genotyping was carried out using Porcine GGP HD DNA chips (Neogene/Illumina Inc., USA) containing about 70 thousand SNP. After the quality control, 42981 polymorphic SNP were selected for analysis. Search of reference sequences (rs) and clarification of their localization was carried out using the Ensembl database (http://www.ensembl.org). Functional gene annotations were performed using the GeneCards database (http://www.genecards.org/). Analysis of the maintenance of genetic equilibrium showed the presence of 990 SNPs with the absence of one of the homozygous genotypes $(2.30 \%$ of the total number of polymorphic SNPs), which were distributed among all pig chromosomes, including 205 SNPs, which were in the linkage disequilibrium $(0.48 \%)$. Chromosomes SSC9 (0.8 \%), SSC5 $(0.77 \%)$, SSC7 $(0.68 \%)$ and $\operatorname{SSC} 2(0.68 \%)$ were characterized by the highest ratio of SNPs in linkage disequilibrium, while chromosomes SSC13 $(0.28 \%), \operatorname{SSC} 4(0.29 \%)$ and SSC10 $(0.30 \%)$ were the lowest. For 52 SNPs, of which 25 SNPs were localized within genes, differences in observed and expected heterozygosity frequencies were statistically significant $(\mathrm{p}<0.01)$. Among SNPs located in intergenic regions, two SNPs (rs81350198 and rs81337222) are associated with important phenotypes from earlier GWAS studies. For 12 of the 25 identified positional candidate genes (OR4C45, EPHB4, EML4, SLC4A1AP, ZFAT, CELSR2, NEGR1, LRRC32, MYOCD, HUNK, $R P H 3 A$, and $D O C K 1$ ), we obtained the information on their role in various processes in organisms of mammals, including nervous system development, angiogenesis, cardiogenesis, cell differentiation, apoptosis and many others. The integration of DNA markers associated with lethal phenotypes into breeding programs, in addition to DNA markers identified by GWAS studies, will significantly improve the efficiency of marker and genomic breeding programs in pigs. 
Keywords: pigs, linkage disequilibrium, lethal variants, LoF (loss of function), single nucleotide polymorphisms.

\section{REFERENCES}

1. Pope W.F. Embryonic mortality in swine. In: Embryonic mortality in domestic species. M.T. Zavy, R.D. Geisert (eds.). CRC Press, Boca Raton, 1994: 53-77.

2. Bickhart D.M., Hou Y., Schroeder S.G., Alkan C., Cardone M.F., Matukumalli L.K., Song J., Schnabel R.D., Ventura M., Taylor J.F., Garcia J.F., Van Tassell C.P., Sonstegard T.S., Eichler E.E., Liu G.E. Copy number variation of individual cattle genomes using next-generation sequencing. Genome Res., 2012, 22(4): 778-790 (doi: 10.1101/gr.133967.111).

3. Zinov'eva N.A. Haplotypes affecting fertility in Holstein cattle. Sel'skokhozyaistvennaya biologiya [Agricultural Biology], 2016, 51(4): 423-435 (doi: 10.15389/agrobiology.2016.4.423eng).

4. Gorbach D., Mote B., Totir L., Fernando R., Rothschild M. Polydactyl inheritance in the pig. Journal of Heredity, 2010, 101(4): 469-475 (doi: 10.1093/jhered/esq037).

5. Howard D.M., Pong-Wong R., Knap P.W., Woolliams J.A. Use of haplotypes to identify regions harbouring lethal recessive variants in pigs. Genetics Selection Evolution, 2017, 49: 57 (doi: 10.1186/s12711-017-0332-3).

6. Häggman J., Uimari P. Novel harmful recessive haplotypes for reproductive traits in pigs. $J$. Anim. Breed. Genet., 2017, 134(2): 129-135 (doi: 10.1111/jbg.12240).

7. Derks M.F.L., Gjuvsland A.B., Bosse M., Lopes M.S., van Son M., Harlizius B., Tan B.F., Hamland H., Grindflek E., Groenen M.A.M., Megens H.-J. Loss of function mutations in essential genes cause embryonic lethality in pigs. PLoS Genet., 2019, 15(3): e1008055 (doi: 10.1371/journal.pgen.1008055).

8. Purcell S., Neale B., Todd-Brown K., Thomas L., Ferreira M.A.R., Bender D., Maller J., Sklar P., de Bakker P.I.W., Daly M.J., Sham P.C. PLINK: A tool set for whole-genome association and population-based linkage analyses. The American Journal of Human Genetics, 2007, 81(3): 559-575 (doi: 10.1086/519795).

9. Drag M., Hansen M.B., Kadarmideen H.N. Systems genomics study reveals expression quantitative trait loci, regulator genes and pathways associated with boar taint in pigs. PLoS ONE, 2018, 13(2): e0192673 (doi: 10.1371/journal.pone.0192673).

10. Fernandes L.T., Ono R.K., Ibelli A.M.G., Lagos E.B., Morés M.A.Z., Cantão M.E., Lorenzetti W.R., Peixoto J. de O., Pedrosa V.B., Ledur M.C. Novel putative candidate genes associated with umbilical hernia in pigs. Proc. World Congress on Genetics Applied to Livestock Production. Electronic Poster Session. Species. Porcine 2. Auckland, New Zealand, 2018: 743.

11. Long Y., Su Y., Ai H., Zhang Z., Yang B., Ruan G., Xiao S., Liao X., Ren J., Huang L., Ding N. A genome-wide association study of copy number variations with umbilical hernia in swine. Anim. Genet., 2016, 47(3): 298-305 (doi: 10.1111/age.12402).

12. Borisevich D.I., Shatalova L.V., Korostin D.O., Il'inskii V.V. Vestnik Rossiiskogo gosudarstvennogo meditsinskogo universiteta, 2016, 1: 20-24 (in Russ.).

13. Braun T., Voland P., Kunz L., Prinz C., Gratzl M. Enterochromaffin cells of the human gut: sensors for spices and odorants. Gastroenterology, 2007, 132(5): 1890-1901 (doi: 10.1053/j.gastro.2007.02.036).

14. Kaji I., Karaki S., Kuwahara A. Effects of luminal thymol on epithelial transport in human and rat colon. American Journal of Physiology-Gastrointestinal and Liver Physiology, 2011, 300(6): G1132-G1143 (doi: 10.1152/ajpgi.00503.2010).

15. Becerikli M., Merwart B., Lam M.C., Suppelna P., Rittig A., Mirmohammedsadegh A., Stricker I., Theiss C., Singer B.B., Jacobsen F., Steinstraesser L. EPHB4 tyrosine-kinase receptor expression and biological significance in soft tissue sarcoma. Int. J. Cancer., 2015, 136(8): 17811791 (doi: 10.1002/ijc.29244).

16. Gerety S.S., Wang H.U., Chen Z.F., Anderson D.J. Symmetrical mutant phenotypes of the receptor EphB4 and its specific transmembrane ligand ephrin-B2 in cardiovascular development. Molecular Cell, 1999, 4(3): 403-414 (doi: 10.1016/s1097-2765(00)80342-1).

17. Fry A.M., O'Regan L., Montgomery J., Adib R., Bayliss R. EML proteins in microtubule regulation and human disease. Biochemical Society Transactions, 2016, 44(5): 1281-1288 (doi: 10.1042/BST20160125).

18. Xu Q., Deller M.C., Nielsen T.K., Grant J.C., Lesley S.A., Elsliger M.A., Deacon A.M., Wilson I.A. Structural insights into the recognition of phosphopeptide by the FHA domain of kanadaptin. PLoS ONE, 2014, 9(9): e107309 (doi: 10.1371/journal.pone.0107309).

19. Tsunoda T., Doi K., Ishikura S., Luo H., Nishi K., Matsuzaki H., Koyanagi M., Tanaka Y., Okamura T., Shirasawa S. Zfat expression in ZsGreen reporter gene knock in mice: Implications for a novel function of Zfat in definitive erythropoiesis. International Journal of Molecular Medicine, 2018, 42(5): 2595-2603 (doi: 10.3892/ijmm.2018.3806).

20. Tsunoda T., Takashima Y., Tanaka Y., Fujimoto T., Doi K., Hirose Y., Koyanagi M., Yo- 
shida Y., Okamura T., Kuroki M., Sasazuki T., Shirasawa S. Immune-related zinc finger gene ZFAT is an essential transcriptional regulator for hematopoietic differentiation in blood islands. Proceedings of the National Academy of Sciences, 2010, 107(32): 14199-14204 (doi: 10.1073/pnas. 1002494107).

21. Ji H.Y., Yang B., Zhang Z.Y., Ouyang J., Yang M., Zhang X.F., Zhang W.C., Su Y., Zhao K.W., Xiao S.J., Yan X.M., Ren J., Huang L.S. A genome-wide association analysis for susceptibility of pigs to enterotoxigenic Escherichia coli F41. Animal, 2016, 10(10): 1602-1608 (doi: 10.1017/S1751731116000306).

22. Tissir F., Qu Y., Montcouquiol M., Zhou L., Komatsu K., Shi D., Fujimori T., Labeau J., Tyteca D., Courtoy P., Poumay Y., Uemura T., Goffinet A.M. Lack of cadherins Celsr2 and Celsr3 impairs ependymal ciliogenesis, leading to fatal hydrocephalus. Nat. Neurosci., 2010, 13: 700-707 (doi: 10.1038/nn.2555).

23. Schäfer M., Bräuer A.U., Savaskan N.E., Rathjen F.G., Brümmendorf T. Neurotractin/kilon promotes neurite outgrowth and is expressed on reactive astrocytes after entorhinal cortex lesion. Molecular and Cellular Neuroscience, 2005, 29(4): 580-590 (doi: 10.1016/j.mcn.2005.04.010).

24. Lee K.-T., Byun M.-J., Kang K.-S., Park E.-W., Lee S.-H., Cho S., Kim H.Y., Kim K.-W., Lee T.H., Park J.-E., Park W.C., Shin D.H., Park H.-S., Jeon J.-T., Choi B.-H., Jang G.-W., Choi S.-H., Kim D.-W., Lim D., Park H.-S., Park M.-R., Ott J., Schook L. B., Kim T.-H., Kim H. Neuronal genes for subcutaneous fat thickness in human and pig are identified by local genomic sequencing and combined SNP association study. PLoS ONE, 2011, 6(2): e16356 (doi: 10.1371/journal.pone.0016356).

25. Stockis J., Colau D., Coulie P.G., Lucas S. Membrane protein GARP is a receptor for latent TGF- $\beta$ on the surface of activated human Treg. Eur. J. Immunol., 2009, 39(12): 3315-3322 (doi: 10.1002/eji.200939684).

26. Kosova G., Scott N.M., Niederberger C., Prins G.S., Ober C. Genome-wide association study identifies candidate genes for male fertility traits in humans. The American Journal of Human Genetics, 2012, 90(6): 950-961 (doi: 10.1016/j.ajhg.2012.04.016).

27. Hoofnagle M.H., Neppl R.L., Berzin E.L., Teg Pipes G.C., Olson E.N., Wamhoff B.W., Somlyo A.V., Owens G.K. Myocardin is differentially required for the development of smooth muscle cells and cardiomyocytes. American Journal of Physiology-Heart and Circulatory Physiology, 2011, 300(5): H1707-H1721 (doi: 10.1152/ajpheart.01192.2010).

28. Lin C.-C., Huang C.-C., Lin K.-H., Cheng K.-H., Yang D.-M., Tsai Y.-S., Ong R.-Y., Huang Y.N., Kao L-.S. Visualization of Rab3A dissociation during exocytosis: a study by total internal reflection microscopy. J. Cell. Physiol., 2007, 211(2): 316-326 (doi: 10.1002/jcp.20938).

29. Laurin M., Fradet N., Blangy A., Hall A., Vuori K., Cóté J.-F. The atypical Rac activator Dock180 (Dock1) regulates myoblast fusion in vivo. Proceedings of the National Academy of Sciences, 2008, 105(40): 15446-15451 (doi: 10.1073/pnas.0805546105).

30. Yang Y., Zhou R., Mu Y., Hou X., Tang Z., Li K. Genome-wide analysis of DNA methylation in obese, lean, and miniature pig breeds. Scientific Reports, 2016, 6: 30160 (doi: 10.1038/srep30160).

31. Ponsuksili S., Zebunke M., Murani E., Trakooljul N., Krieter J., Puppe B., Schwerin M., Wimmers K. Integrated Genome-wide association and hypothalamus eQTL studies indicate a link between the circadian rhythm-related gene PER1 and coping behavior. Scientific Reports, 2015, 5: 16264 (doi: 10.1038/srep16264).

32. Belous A.A., Sermyagin A.A., Kostyunina O.V., Brem G., Zinov'eva N.A. Study of genetic architecture of feed conversion rate in duroc young boars (Sus scrofa) based on the genomewide SNP analysis. Sel'skokhozyaistvennaya biologiya [Agricultural Biology], 2019, 54(4): 705-712 (doi: 10.15389/agrobiology.2019.4.705rus). 